\title{
Present Without Unequivocal Progression
}

National Cancer Institute

\section{Source}

National Cancer Institute. Present Without Unequivocal Progression. NCI Thesaurus.

Code C126055.

There is evidence of disease without evidence of unequivocal progression. 